\title{
Clinical and sonographic estimation of fetal weight and correlation with the birth weight: a research article
}

\author{
Alvencia Vaz ${ }^{1}$, Aheibam Bidya Devi ${ }^{1 *}$, Naorem Nabakishore Singh ${ }^{1}$, \\ Wahengbam Jatishwor Singh ${ }^{2}$, Laiphrakpam Ranjit Singh ${ }^{1}$, Dylan Momin ${ }^{1}$
}

\begin{abstract}
${ }^{1}$ Department of Obstetrics and Gynecology, Regional Institute of Medical Sciences, Imphal, Manipur, India
${ }^{2}$ Department of Radiodiagnosis, Regional Institute of Medical Sciences, Imphal, Manipur, India
\end{abstract}

Received: 05 June 2019

Accepted: 09 July 2019

*Correspondence:

Dr. Aheibam Bidya Devi,

E-mail: aheibambidya@gmail.com

Copyright: (c) the author(s), publisher and licensee Medip Academy. This is an open-access article distributed under the terms of the Creative Commons Attribution Non-Commercial License, which permits unrestricted non-commercial use, distribution, and reproduction in any medium, provided the original work is properly cited.

\begin{abstract}
Background: Accurate estimation of fetal weight is of paramount importance in the management of labour and childbirth. In developing countries including India, estimation of fetal weight by clinical method is important as ultrasound is not available in all health care settings. In view of this, the present study was conducted to estimate the fetal weight assessed by clinical and ultrasound method and correlating with the birth weight.

Methods: A cross-sectional study was conducted to estimate fetal weight clinically by using Johnson's formula and sonographically based on Hadlock's formula in the Department of Obstetrics and Gynecology in collaboration with Department of Radiodiagnosis, Regional Institute of Medical Sciences, Imphal from October 2016 to March 2018. The study consisted of 525 pregnant women between 37 to 40 weeks of gestation in whom delivery was anticipated within one week of fetal weight estimation by clinical and ultrasound method and correlating it with the baby's birth weight measured immediately after delivery. Analysis was done using Chi-square and Student's t-test and p-value of $<0.05$ was taken as significant.

Results: Both methods showed positive correlation with birth weight but clinical method $(r=0.925)$ had stronger correlation compared with ultrasound method ( $\mathrm{r}=0.508)$.

Conclusions: Fetal weight estimation using Johnson's formula had stronger correlation with the birth weight than ultrasound method and hence, useful for developing countries and all health care workers may be sensitized about the method.
\end{abstract}

Keywords: Birth weight, Fetal weight, Hadlock’s formula,Johnson's formula, Symphysio-fundal height, Ultrasound

\section{INTRODUCTION}

During the last decade, estimation of fetal weight has been incorporated into the standard routine antepartum evaluation of high risk pregnancies. Knowledge of expected birth weight estimation is attractive to clinicians as it is an important variable affecting childbirth and perinatal mortality. Both low birth weight and large for gestational age at delivery are associated with an increased risk of perinatal complications. Management of pregnancy with diabetic complications, vaginal birth after caesarean section and breech presentation are guided by the estimated fetal weight. ${ }^{1}$ In preterm deliveries and intrauterine growth restriction, perinatal counselling on the likelihood of survival, optimal route of delivery or the level of hospital where the delivery shall occur is 
completely based on the estimated fetal weight. ${ }^{2}$ Precise estimation of fetal weight will help in successful management of labour and care of newborn and prepare for any complications associated with low birth weight as well as macrosomia.

Different methods of estimating fetal weight have been tried in different parts of the world in search of the ideal method. Worldwide, clinical methods are used extensively because they are both convenient and virtually costless. The different formulae used clinically are Johnson's and Dare's formula. ${ }^{3}$ In maternal self estimation, several studies showed that parous women can subjectively assess the weight of their fetus just as accurately as a physician. ${ }^{4}$ Obstetric ultrasonography is the most modern method for assessing the fetal weight inutero. MRI and 3D ultrasound are promising new modalities that may improve actual fetal weight estimation by providing volumetric assessment of the fetus. As volumetric measurement can improve fetal weight estimation, several technical and methodological problems need to be overcome before this technique is adopted into routine practice. It is also unclear at present which fetal organ system should be included in volumetry in order to achieve an accurate weight estimate.

Ultrasound examination involves measurement of multiple biometric parameters that are incorporated into a formula for calculating estimated fetal weight. It is one of the most sensitive method for estimating fetal weight with error ranging from $\pm 6-11 \% .^{5}$ Various ultrasound parameters like biparietal diameter (BPD), head circumference (HC), abdominal circumference (AC), femur length (FL), anteroposterior trunk diameter (APTD), transverse trunk diameter (TTD), foetal trunk cross-sectional area (FTA)2, can be used singly or in combination for fetal weight estimation. The different algorithms used worldwide are Hadlock's formula, Shepard formula, Tokyo university formula, Campbell, Hansman, Sabbagha, Warsof, etc. To improve the accuracy of fetal weight estimation, sonographic models that are based on 3 or 4 fetal biometric indices are preferred. ${ }^{6}$

Abdulrazak $\mathrm{H}$ et al, found that clinical fetal weight estimation was relatively accurate and comparable to ultrasound. ${ }^{7}$ Some studies showed that ultrasound fetal weight estimation was superior to clinical prediction. ${ }^{2,8}$ Few others indicated that clinical method was simple and more reliable than ultrasound. ${ }^{9}$

Clinical estimation of fetal weight is, therefore, an important and necessary skill in the management of obstetric patients in developing countries because of its simplicity in low resource settings as sophisticated instrument like ultrasound is not available everywhere. ${ }^{1,2}$

Hence, the study was conducted to assess the fetal weight clinically by Johnson's formula and by ultrasound using
Hadlock's formula at term and correlating it with the birth weight of the baby. ${ }^{10,11}$

\section{METHODS}

It was a cross-sectional study carried out in the Department of Obstetrics and Gynecology in collaboration with the Department of Radio-diagnosis, Regional Institute of Medical Sciences, Imphal for a period of one and a half years on a total of 525 patients and consecutive sampling was done.

\section{Inclusion criteria}

Antenatal women between 37 weeks to 40 weeks of gestation with singleton pregnancy with cephalic presentation in spontaneous labour or those admitted for elective caesarean. Patients who were obese or having medical conditions like anemia, hypertensive disorders, gestational diabetes and heart diseases were also included in the study irrespective of age, parity, height and weight.

\section{Exclusion criteria}

Multiple gestation, presentation other than vertex, preterm or post term, ruptured membranes, oligohydramnios or polyhydramnios, pregnancy with uterine or abdominal mass, fetal demise, fetal anomalies

\section{Study tools}

- Clinical Examination: Measurement of symphysiofundal height by using non elastic centimetre tape followed by abdominal and per vaginal examination was done.

- The ultrasound machine model used for sonographic estimation was Toshiba MODEL SSA-580A Nemio $\mathrm{XG}$ numbered as $2 \mathrm{~B} 730-818 \mathrm{EN} * \mathrm{E}$ manufactured in Japan, with Toshiba PVM-375AT (3-6Mhz) convex curved Array Transducer and Toshiba PLM-1204AT (8-14Mhz) linear array with M mode and grey scale for imaging and calculating foetal heart rate with good resolution. Bi-parietal diameter (BPD), abdominal circumference (AC) and femur length (FL) were measured and the weight was calculated automatically by the ultrasound machine using the Hadlock's reference table.

- Carelabmed electronic baby scale Model PT-951 made in India was used for birth weight measurement after delivery.

\section{Procedure of study}

Prior to allocation the participants were counseled regarding the study and explained that ultrasound which was routinely used for obstetric cases was a non invasive and safe procedure and consent was obtained in a designated form. A comprehensive history was taken for each patient followed by general physical examination. Routine haematological and biochemical investigations 
were carried out. Fetal weight estimation was done by clinical and ultrasound methods. If the delivery did not occur within a week of the fetal weight estimation, the estimations were repeated and the repeat estimations were taken into consideration.

\section{Foetal weight estimation by Johnson's formula ${ }^{10}$}

- After emptying bladder, patient was placed in supine position with legs flat on the bed, extended both at the hips and knee. After correction of dextrorotation McDonald's measurement of height of fundus from the upper edge of the symphysis pubis following the curvature of the abdomen was taken with centimetre tape. The upper hand was firmly against the top of the fundus with the measuring tape pressing between the index and middle finger

- Station of presenting part was assessed by abdominal and by vaginal examination

- Fetal weight was estimated as follows:

Fetal weight $(\mathrm{g})=($ McDonald's measurement-S $) \times 155$

$\mathrm{S}=13$, when presenting part was at minus station

$\mathrm{S}=12$, when presenting part was at 0 station

$\mathrm{S}=11$, when presenting part was at +1 station.

If women weighed more than $91 \mathrm{~kg}, 1 \mathrm{~cm}$ was subtracted from fundal height.

Fetal weight estimation by Hadlock's formula using sonography. ${ }^{11}$

Based on biparietal diameter (BPD), abdominal circumference (AC), and femur length (FL), the ultrasound machine calculated the fetal weight automatically using Hadlock's reference table.

$\log 10(\mathrm{EFW})=1.335-0.0034 \times \mathrm{AC} \times \mathrm{FL}+0.0316 \times$ $\mathrm{BPD}+0.0457 \times \mathrm{AC}+0.1623 \times \mathrm{FL}$

Finally, the accuracy of both the methods was evaluated comparing with the birth weight of baby after delivery.

Baby scale made by Carelabmed was used to check baby's birth weight immediately after delivery. The accuracy of the weighing scale at the labour ward was validated prior to the study. A known 2000 grams weight placed on the weighing scale gave an accurate result before the scale was used for the investigation. Care was taken to ensure that the calibrated scale was on zero reading before use.

\section{Statistical analysis}

Data was checked for consistency and completeness and analyzed by an appropriate data base software programmer (SSPS version 21.0 IBM). Data collected was analyzed using descriptive statistics namely mean, percentages and standard deviation and analytical studies were done using Chi-square and Student's t-test and pvalue of $<0.05$ was taken as significant.

\section{RESULTS}

As shown in Table 1, $84.76 \%$ of participants had fetal weight between 2500-3500 estimated by Johnson's formula with mean weight being 3093.26 \pm 371.93 (grams).

Table 1: Distribution of participants according to estimated fetal weight by Johnson's formula (grams).

\begin{tabular}{|lll|}
\hline $\begin{array}{l}\text { Weight by Johnson's } \\
\text { formula (grams) }\end{array}$ & $\begin{array}{l}\text { No. of } \\
\text { participants }\end{array}$ & $\%$ \\
\hline$<2500$ & 12 & 2.29 \\
\hline $2500-3500$ & 445 & 84.76 \\
\hline $3501-4500$ & 68 & 12.95 \\
\hline$>4500$ & 0 & 0 \\
\hline Total & $\mathbf{5 2 5}$ & $\mathbf{1 0 0}$ \\
\hline
\end{tabular}

As shown in Table 2, 72\% of participants had fetal weight between 2500-3500 estimated by Hadlock's formula with mean birth weight being 2990.89 \pm 448.39 (grams).

Table 2: Distribution of participants according to estimated fetal weight by Hadlock's formula (grams).

\begin{tabular}{|lll|}
\hline $\begin{array}{l}\text { Weight by Hadlock's } \\
\text { (grams) }\end{array}$ & $\begin{array}{l}\text { No. of } \\
\text { participants }\end{array}$ & $\%$ \\
\hline$<2500$ & 76 & 14.48 \\
\hline $2500-3500$ & 378 & 72.00 \\
\hline $3501-4500$ & 70 & 13.33 \\
\hline$>4500$ & 1 & 0.19 \\
\hline Total & $\mathbf{5 2 5}$ & $\mathbf{1 0 0}$ \\
\hline
\end{tabular}

As shown in Table 3,79.81\% of participants had babies with birth weight between 2500-3500 with mean weight being $3090.47 \pm 428.98$ (grams).

Table 3: Distribution of babies according to birth weight (grams).

\begin{tabular}{|lll|}
\hline Birth weight in grams & No. of participants & $\%$ \\
\hline$<2500$ & 28 & 5.33 \\
\hline $2500-3500$ & 419 & 79.81 \\
\hline $3501-4500$ & 77 & 14.67 \\
\hline$>4500$ & 1 & 0.19 \\
\hline Total & $\mathbf{5 2 5}$ & $\mathbf{1 0 0}$ \\
\hline
\end{tabular}

The data was tested using Chi-square test and Fisher's Exact test.

In the study (Table 4, Figure 1a and 1b), there was overestimation of fetal weight by Johnson's formula in $64.3 \%$ and by ultrasound in $39.3 \%$ of cases in low birth weight babies (birth weight $<2500$ grams). In birth 
weight between 2500 to 3500 grams, Johnson's formula predicted $98.1 \%$ and ultrasound predicted $77.1 \%$ cases accurately, while in birth weight above 3500 grams, Johnson's formula predicted accurately in $79.5 \%$ of cases with underestimation in $20.5 \%$ and ultrasound predicted accurately in only $41 \%$ cases with underestimation in $59 \%$ of cases.

Table 4: Comparison of weight by Johnson's formula and Hadlock's formula with actual birth weight of babies.

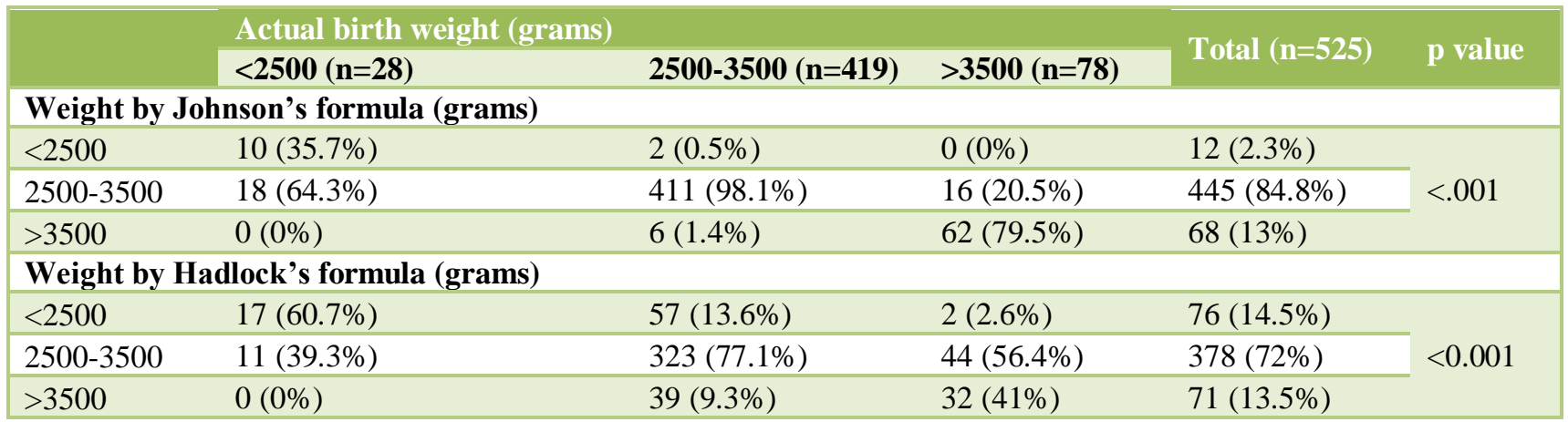

Table 5: Comparison of weight measured by Johnson's and Hadlock's formula with birth weight.

\begin{tabular}{|lcclll|} 
& Min-Max & Mean \pm SD & $\begin{array}{l}\text { Difference } \\
\text { with respect to } \\
\text { birth weight }\end{array}$ & $\begin{array}{l}\text { t value with } \\
\text { respect to } \\
\text { birth weight }\end{array}$ & $\begin{array}{l}\text { p value with } \\
\text { respect to birth } \\
\text { weight }\end{array}$ \\
\hline $\begin{array}{l}\text { Weight by Johnson's } \\
\text { formula (grams) }\end{array}$ & $2015.00-4031.00$ & $3093.26 \pm 371.93$ & 2.790 & 0.387 & 0.699 \\
\hline $\begin{array}{l}\text { Weight by Hadlock's } \\
\text { formula (grams) }\end{array}$ & $1717.00-4144.00$ & $2990.89 \pm 448.39$ & 99.587 & 5.242 & $<0.001$ \\
\hline Birth weight (grams) & $1440.00-4350.00$ & $3090.47 \pm 428.99$ & - & - & - \\
\hline
\end{tabular}

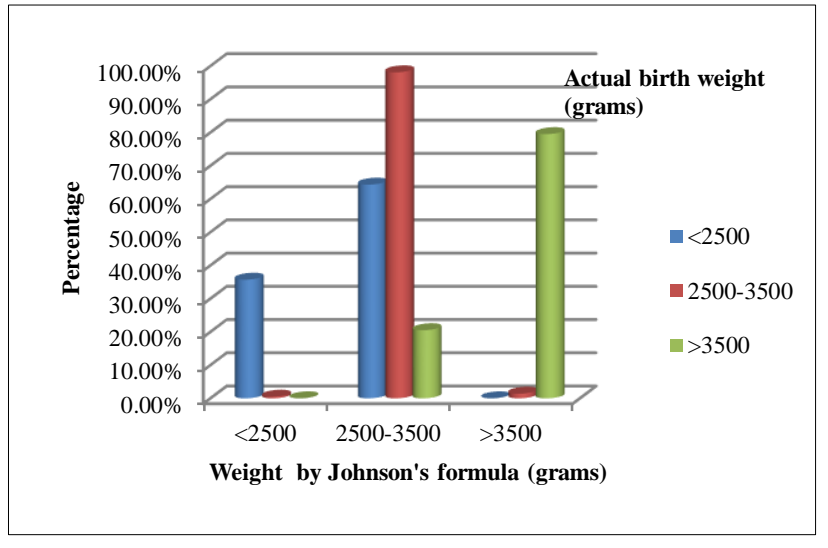

Figure 1a: Bar diagram comparing weight estimated by Johnson's formula with birth weight.

Data was tested using Student's t test to find the significance of study parameters. Fetal weight estimated by Johnson's formula, when compared to actual birth weight (3093.26 versus 3090.47 grams), the difference of 2.790 is not statistically significant $(\mathrm{p}=0.699)$ confirming that Johnson's method of fetal weight estimation correlated well with birth weight with least difference compared to fetal weight estimation by Hadlock's formula ( Table 5).

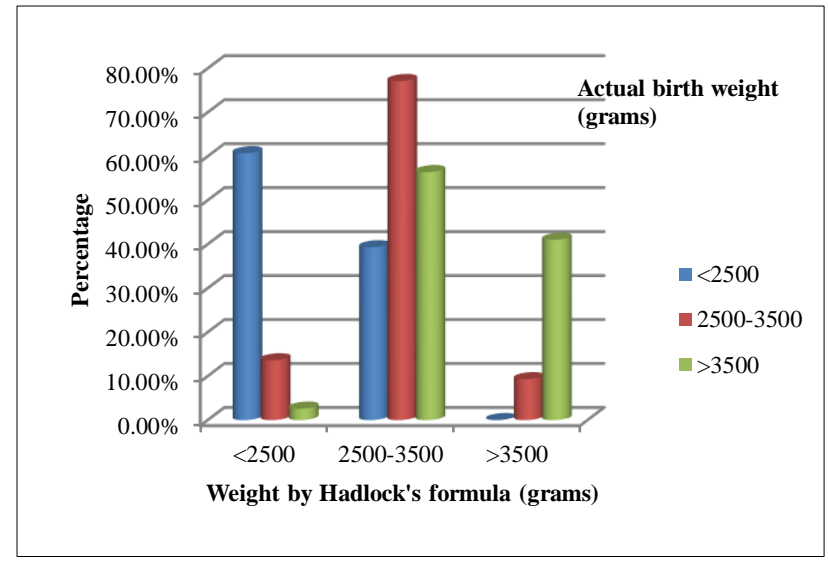

Figure 1b: Bar diagram comparing weight estimated by Hadlock's formula with birth weight.

Pearson correlation between study variables was used to find the degree of relationship. In the present study, the correlation coefficients for the fetal weight estimated by Johnson's formula and Hadlock's formula compared to the birth weight were 0.925 and 0.508 respectively confirming that Johnson's method of measurement of weight correlated with birth weight with least difference compared to Hadlock's method (Table 6). 
Table 6: Pearson correlation between the estimated fetal weight by Johnson's formula, Hadlock's formula and birth weight.

\begin{tabular}{|lll|}
\hline $\begin{array}{l}\text { Weight by Johnson's versus } \\
\text { weight by Hadlock's formula }\end{array}$ & 0.493 & $<0.001$ \\
\hline $\begin{array}{l}\text { Weight by Johnson's formula } \\
\text { versus birth weight }\end{array}$ & 0.925 & $<0.001$ \\
\hline $\begin{array}{l}\text { Weight by Hadlock's formula } \\
\text { versus birth weight }\end{array}$ & 0.508 & $<0.001$ \\
\hline
\end{tabular}

\section{DISCUSSION}

In the present study, estimation of fetal weight by both clinical and ultrasound methods were done and correlated with the birth weight. Most of the babies (79.81\%) had birth weight between 2500 grams and 3500 grams which were similar to the findings in the study done by Kumari A et al, (73\%) and Njoku C et al, (82\%). ${ }^{3,12}$ Multiparous women constituted $56.6 \%$ of the study population and nulliparous only $43.4 \%$. The mean period of gestation at examination was $39.42 \pm 0.43$ weeks and the mean period of gestation at delivery was $39.55 \pm 0.45$ weeks. The low birth babies (birth weight $<2500$ grams) accounted for $5.3 \%$ and normal weight babies (birth weight between 2500 to $<4000$ grams) were $91.9 \%$ (482/525) while macrosomic babies (birth weight $>4000$ grams) were $2.8 \%(15 / 525)$. The percentage of low birth weight babies in our study was $5.3 \%(28 / 525)$ and was similar to the observation by Njoku $\mathrm{C}$ et al, $(6 \%) .^{12}$

The mean birth weight in this study was $3090.47 \pm 428.98$ grams. This was slightly lower than $3242 \pm 508$ grams and $3254 \pm 622$ grams reported by Njoku C et al, and Shittu AS et al, respectively. ${ }^{12,13}$ The reason might be due to several factors affecting birth weight such as ethnic, regional and socioeconomic factors.

In the present study, the mean estimated fetal weight by Johnson's formula 3093.26 \pm 371.93 grams was closer to the mean of actual birth weight $3090.47 \pm 428.98$ grams when compared with mean estimated fetal weight by Hadlock's formula which was $2990.89 \pm 448.39$ grams. Similarly, Ratwani K et al, found that Hadlock's formula showed a mean weight of 2540 grams whereas mean weight at the time of delivery was 2900 grams and mean weight by Johnson's formula came out to 2890 grams which was almost equivalent to mean birth weight i.e. 2900 grams, thus stating that the clinical method could be taken as reliable predictor for estimation of fetal weight. ${ }^{9}$

There was overestimation of fetal weight by Johnson's formula in $64.3 \%$ and by ultrasound in $39.3 \%$ of cases in low birth weight babies in the present study. In birth weight between 2500 to 3500 grams, Johnson's formula predicted $98.1 \%$ and ultrasound predicted $77.1 \%$ cases accurately, while in birth weight above 3500 grams, Johnson's formula predicted accurately in $79.5 \%$ of cases with underestimation in $20.5 \%$ of cases, while ultrasound predicted accurately in only $41 \%$ cases with underestimation in $59 \%$ cases.

A study conducted by Sherman DJ et al, showed similar results with ultrasound being more accurate than clinical method for fetal weight less than 2500 grams, whereas the clinical method was more accurate than ultrasound for fetal weight between 2500 to 4000 grams. ${ }^{1}$ These findings were similar to study done by Melamed $\mathrm{N}$ et al, which stated that the accuracy of weight estimation decreased at the extremes of birth weight, leading to overestimation in low birth weight categories as opposed to underestimation when birth weight exceeds 4000 grams. ${ }^{6}$ Also Shittu AS et al, observed that clinical estimation of birth weight was as accurate as routine ultrasonographic estimation, except in low birth babies. ${ }^{13}$ Titapant $\mathrm{V}$ et al, also found that among babies with birth weight less than 2500 grams, ultrasound estimation performed slightly better than the clinical estimation and that every method underestimated the fetal weight when a baby weighed more than 4000 grams. ${ }^{14}$ However, ultrasound was found to be more accurate in the range of 2500-3500 grams in a study by Kavitha B et al. ${ }^{8}$

The correlation coefficients for the fetal weight estimated by Johnson's formula and Hadlock's formula in this study compared to the birth weight were 0.925 and 0.508 respectively confirming that Johnson's method of measurement of weight correlated with birth weight with least difference compared to Hadlock's method. Similar findings were also found in a study done by Ugwu EO et al in which birth weight had a strong positive correlation with both clinically and sonographically estimated fetal weight $\left(r=0.71\right.$ and $r=0.69$ respectively). ${ }^{15}$ A study done by Njoku $\mathrm{C}$ et al, stated that the correlation coefficient for the clinical and ultrasound methods compared to actual birth weight were 0.740 and 0.847 respectively and both correlated positively with the actual birth weight. ${ }^{12}$ Noumi $G$ et al, noted that the coefficient of correlation between the clinical and sonographic estimation of fetal weight and the actual birth weight was 0.59 and 0.65 respectively and concluded that sonographic estimation of birth weight offered no advantage over clinical estimation of birth weight and both were comparable. ${ }^{16}$ Kumari et al, Baum JD et al, Shittu AS et al, Prechapanich J et al, Titapant V et al, Torloni MR et al and Ashwini I et al, also concluded that easily measurable obstetric parameters, with simple instruments requiring minimal manpower training were equally accurate as ultrasound in predicting fetal weight. $3,13,14,17,18,20$

A study done by Kavitha B et al, the authors concluded that ultrasound estimation of fetal weight was more reliable method than Johnson's formula and could be used in breech and other mal-presentations where Johnson's formula could not be applied and also that it had high sensitivity and specificity to estimate fetal weight and correlated significantly with birth weight. ${ }^{7}$ In other studies done by Annapurna K et al, Zahran M et al, 
and Helali EA et al, the authors concluded that ultrasound estimation by Hadlock's formula was superior to clinical estimation by Johnson's formula which differed from our study. ${ }^{21-23}$

A study conducted by Yiheyis A et al, showed that the accuracy of Johnson's formula was $38 \%$ and stated to be inaccurate in the study population of South Western Ethiopia. ${ }^{24}$ Similarly, Ugwa EA et al, found that correlation between clinical estimation and actual birth weight was weak and also found significant error in estimating fetal weight by ultrasound and opined that it could lead to unnecessary obstetrical intervention. ${ }^{25}$

The observations implied that there was clearly a role for clinical estimation of birth weight as a diagnostic tool, suggesting that clinical estimation was sufficient to manage labour and delivery in a term pregnancy especially in resource poor settings as well as for early detection of fetal weight abnormalities and the proper management of pregnancy.

\section{CONCLUSION}

Clinical estimation correlated well with birth weight and is sufficient to manage labour and delivery in resource poor settings. Clinical fetal weight estimation should be taught to all health care workers as sonographic fetal weight estimation requires expensive equipment and is not available in all health care facilities. It can be used as a routine screening tool for all pregnant women at term.

\section{ACKNOWLEDGMENTS}

Authors would like to thank all the patients who willingly participated in the study and to our seniors, colleagues and staff members for their guidance, help and cooperation.

\section{Funding: No funding sources}

Conflict of interest: None declared

Ethical approval: The study was approved by the Institutional Ethics Committee

\section{REFERENCES}

1. Sherman DJ, Arieli S, Tovbin J, Siegel G, Caspi E, Bukovsky I. A comparison of clinical and ultrasonic estimation of fetal weight. Obstet Gynecol. 1998;91(2):212-7.

2. Chauhan SP, Hendrix NW, Magann EF, Morrison JC, Kenney SP, Devoe LD. Limitations of clinical and sonographic estimates of birth weight: experience with 1034 parturients. Obstet Gynecol. 1998;91(1):72-7.

3. Kumari A, Goswami S, Muherjee P. Comparative study of various methods of foetal weight estimation in term pregnancy. J South Asian Feder Obst Gynae. 2013;5(1):22-5.
4. Herrero RL, Fitzsimmons J. Estimated foetal weight: maternal versus physician estimate. J Reprod Med. 1999;44(8):674-8.

5. Dudley NJ. A systematic review of the ultrasound estimation of fetal weight. Ultrasound Obstet Gynecol. 2005;25(1):80-9.

6. Melamed N, Yogev Y, Meizner I, Mashiach R, Bardin R, Ben-Haroush A. Sonographic foetal weight estimation: which model should be used? J Ultrasound Med. 2009;28(5):617-29.

7. Abdulrazak HA, Mandan DR. Foetal body weight: how far the clinical and Sonographic estimation can coincide and their correlation with the actual birth weight. Iraqi J Comm Med. 2013;2(1):180-3.

8. Kavitha B, Prabhakar GC, Shaivalini K, Suprada K. A comparative study of fetal weight estimation using ultrasound and Johnson's formula and its correlation with actual birth weight. Int $\mathbf{J}$ Sci Res. 2014;3(2):389-90.

9. Ratwani K, Madkar CS, Deshpande HG, Jethani S. Comparative study for estimation of fetal weight by clinical and ultrasonographical methods in term patients. J Evol Med Dent Sci. 2014;3(10):2553-60.

10. Johnson RW, Tosach CE. Estimation of fetal weight using longitudinal mesuration. Am J Obstet Gynecol. 1954;68(3):891-6.

11. Hadlock FP, Harrist RB, Sharman RS, Deter RL, Park SK. Estimation of fetal weight with the use of head, body and femur measurements - a prospective study. Am J Obstet Gynecol. 1985;151(3):333-7.

12. Njoku C, Emechebe C, Odusolu P, Abeshi S, Chukwu C, Ekabua J. Determination of accuracy of foetal weight using ultrasound and clinical foetal weight estimations in Calabar South, South Nigeria. Int Sch Res Notices. 2014;2014:234-9.

13. Shittu AS, Kuti O, Orji EO, Makinde NO, Ogunniyi SO, Ayoola OO, et al. Clinical versus sonographic estimation of fetal weight in southwest Nigeria. J Health Popul Nutr. 2007;25(1):14-23.

14. Titapant V, Chawanpaiboon S, Mingmitpatanakul K. A comparison of clinical and ultrasound estimation of fetal weight. J Med Assoc Thai. 2001;84(9):1251-7.

15. Ugwu EO, Udealor PC, Dim CC, Obi SN, Ozumba $\mathrm{BC}$, Okeke DO, et al. Accuracy of clinical and ultrasound estimation of fetal weight in predicting actual birth weight in Enugu, Southeastern Nigeria. Niger J Clin Pract. 2014;17(3):270-5.

16. Noumi G, Collado-Khoury F, Bombard A, Julliard $\mathrm{K}$, Weiner Z. Clinical and sonographic estimation of foetal weight performed during labour by residents. Am J Obstet Gynecol. 2005;192(5):1407-9.

17. Baum JD, Gussman D, Wirth JC. Clinical and patient estimation of fetal weight versus ultrasound estimation. J Reprod Med. 2002;47(3):194-8.

18. Prechapanich J, Thitadilok W. Comparison of the accuracy of fetal weight estimation using clinical and sonographic methods. J Med Assoc Thai. 2004;87(3):1-7.

19. Torloni MR, Sass N, Sato JL, Renzi AC, Fukuyama M, Rubia LP. Clinical formulas, mother's opinion 
and ultrasound in predicting birth weight. Sao Paulo Med J. 2008;126(3):145-9.

20. Ashwini I, Shweta AK, Sneha S. Clinical versus ultrasonographic fetal weight estimation and its correlation with actual birth weight. Int J Reprod Contracept Obstet Gynecol. 2019;8(2):503-12.

21. Anapurna K, Rama Ch, Ramamani C. A comparative study of fetal weight estimation at term by clinical method and ultrasound method and after delivery. Indian J Appl Res. 2015;5(6):118-23.

22. Zahran M, Tohma AY, Erkaya S, Evliyaoglu O, Colak E, Coskun B. Analysis of the effectiveness of ultrasound and clinical examination methods in fetal weight estimation for term pregnancies. Turk $\mathbf{J}$ Obstet Gynecol. 2015;12(4):220-5.

23. Helali EA, Sayed A, Ali HW. Sonographic versus clinical fetal weight estimation accuracy. Austin Gynecol Case Rep. 2018;3(1):1-5.
24. Yiheyis A, Alemseged F, Segni H. Johnson's formula for predicting birth weight in pregnant mothers at Jimma university teaching hospital, South West Ethiopia. Med J Obstet Gynecol. 2016;4(3):1087-95.

25. Ugwa EA. Advances in clinical estimation of foetal weight before delivery. Niger $\mathrm{J}$ Basic Clin Sci. 2015;12(2):67-73.

Cite this article as: Vaz A, Devi AB, Singh NN, Singh WJ, Singh LR, Momin D. Clinical and sonographic estimation of fetal weight and correlation with the birth weight: a research article. Int J Reprod Contracept Obstet Gynecol 2019;8:3595-601. 